\title{
The Study of Physiological Variations in Electrocardiogram in Late Adolescent
}

Authors

\section{Kadam S.S. ${ }^{1}$, Joshia.S. ${ }^{2}$, Dr Lalit Sankhe ${ }^{3}$}

${ }^{1}$ Associate Professor, Dept of Physiology, Rajiv Gandhi Medical College, Kalwa, Thane, Maharashtra, India Email: kadamswapnali1@gmail.com

${ }^{2}$ Ex-Professor\& Head, Dept of Physiology, Seth G. S. Medical College, Parel, Mumbai, Maharashtra, India Email:drjoshiss44@gmail.com

${ }^{3} \mathrm{MD}$, Community Medicine, Associate Professor, Department of Community Medicine, Grant Government Medical College, Mumbai

\section{ABSTRACT}

To assess the prevalence of physiological variations \& abnormal changes 100 electrocardiograms were recorded of asymptomatic late adolescents (16-19years). This suggests that physiological variations have basis of alterations in the electrochemical processes occurring during various phases of cardiac cycle.This electrocardiograms were analysed for all waves, intervals, heart rate. There was presence ofearly repolarization syndrome, persistent juvenile pattern, sinus arrhythmia, nonspecific $T$ wave changes. Also with this abnormal recording of right atrial hypertrophy was noted.

KEY WORDS: electrocardiogram, physiological variation, adolescents

\section{INTRODUCTION}

The 12 lead electrocardiogram is the most commonly used laboratory test in cardiovascular medicine. A patient with an organic cardiac disorder may have a perfectly normal electrocardiogram and a perfectly normal individual may show nonspecific electrocardiographic abnormalities. ${ }^{1}$ Modern life style (globalization, food habits \& other various stressors) has led to increase in cardiovascular diseases at early age. As per Bayes theorem, in a population with a low prevalence of disease in this case asymptomatic adolescents the number of false positive test (cardiomyopathies, myocardial ischemia) is unacceptably high. ${ }^{2}$ Hence, it is very important to know the physiological variation in late adolescents to prevent misdiagnosis.

\section{PRIMARY OBJECTIVE}

Assess the physiological variation in electrocardiographic changes in late adolescents.

\section{SECONDARY OBJECTIVE}

Assess the incidence of clinically abnormal electrocardiographic findings.

\section{MATERIAL AND METHODS}

A cross sectional observational study was conducted in the department of Physiology of a tertiary medical college of Mumbai after approval of Institution's Ethicalcommittee. A prevalidated structured questionnaire with standardized cardiovascular (CV) system-focused history and physical examinationwas used for selecting the subject. Hundred asymptomatic healthy 
individuals without any history of cardiovascular disease or surgery in age group of 16 to19 years were selected. Informed written consent was taken. The subject's biographical data, height, weight were recorded. Subject was told to relax on a bed for 15 mins before the procedure. 12 lead Electrocardiogram was taken with frequency response of 0.05 to $100 \mathrm{~Hz}$ with a paper speed of $25 \mathrm{~mm} / \mathrm{sec}$. Standardization was done before and after each recording. After applying adequate jelly, all the standard limbs leads, augmented unipolar leads and precordial chest leads from $\mathrm{V}_{1}$ to $\mathrm{V}_{6}$ with minimum 3 complexes were recorded. Appropriate statistical tests were applied.

\section{RESULT \& ANALYSIS:}

\section{Age, Height \& Weight:}

The following table shows the minimum $\&$ maximum ranges $\&$ the mean values obtained.

\begin{tabular}{|l|c|c|c|}
\hline & Age(Yrs) & Height(cms) & Weight(Kgs) \\
\hline Maximum & 19 & 200.66 & 85 \\
\hline Minimum & 15 & 150 & 34 \\
\hline Mean & 17.78 & 169.74 & 56.77 \\
\hline
\end{tabular}

\section{Heart Rate:}

The heart rate was determined by taking the measurements of three cycles from each lead \&

the average was calculated. The distribution of number of cases is given in following table.

\begin{tabular}{|l|c|c|c|c|c|c|c|c|}
\hline Rate/min & 48 & $51-60$ & $61-70$ & $71-80$ & $81-90$ & $91-100$ & $101-110$ & $111-120$ \\
\hline No. of cases & 1 & 1 & 25 & 32 & 25 & 10 & 3 & 3 \\
\hline
\end{tabular}

The rate varied from 48 to $115 / \mathrm{min}$. The mean heart rate was 79/min with standard deviation 12 .

\section{Rhythm:}

Twelve subjects showed sinus arrhythmia. Rest 88 subjects showed normal sinus rhythm. There was no ectopic site of impulse formation or extrasystoles.

\section{P wave:}

$P$ wave was observed only in lead II and $V_{1}$. In lead II, P wave showed duration less than $0.08 \mathrm{sec}$ except at 4 places where it was $0.12 \mathrm{sec}$. It also showed $3 \mathrm{~mm}$ amplitude in 3 subjects with no significant notching /pointed or sharp forms .The negative $\mathrm{P}$ wave in 3 subjects with short duration of $0.04 \mathrm{sec}$. was present only in $\mathrm{V}_{1}$.

\section{PQ/PR Interval:}

The longest duration was taken into account for the calculations. The mean PR interval was 0.1575 . The shortest PQ interval was 0.08 sec. in 2 subjects and longest $0.32 \mathrm{sec}$. in one subject .It was also observed that it was 0.2 sec.in 4 subjects and in another case $0.28 \mathrm{sec}$. which is more than normal.

The association between the two is shown below

\begin{tabular}{|l|c|c|c|}
\hline Rate/min & \multicolumn{3}{|c|}{ Variations of PR interval (seconds) } \\
\hline & Range & Mean & No. of subjects \\
\hline 48 & 0.12 & 0.12 & 1 \\
\hline $51-60$ & 0.2 & 0.2 & 1 \\
\hline $61-70$ & $0.08-0.2$ & 0.14 & 25 \\
\hline $71-80$ & $0.12-0.32$ & 0.22 & 32 \\
\hline $81-90$ & $0.12-0.28$ & 0.2 & 25 \\
\hline $91-100$ & $0.12-0.16$ & 0.14 & 10 \\
\hline $101-110$ & 0.12 & 0.12 & 3 \\
\hline $111-120$ & 0.12 & 0.12 & 3 \\
\hline
\end{tabular}

\section{QRS complex:}

Axis: There was no right or left axis deviation. The minimum and maximum axis were 0 and 100 degree respectively, however, electrical positions of heart observed are: 


\section{JMSCR Vol.||03||Issue ||08||Page 7083-7089||August}

\begin{tabular}{|l|c|c|}
\hline $\begin{array}{l}\text { Vertical / } \\
\text { Semi vertical }\end{array}$ & Indeterminant & $\begin{array}{c}\text { Horizontal / } \\
\text { Semi Horizontal }\end{array}$ \\
\hline $90 \%$ & $2 \%$ & $8 \%$ \\
\hline
\end{tabular}

The correlation between QRS interval with Heart rate is shown below

\begin{tabular}{|l|c|c|c|}
\hline \multirow{2}{*}{$\begin{array}{l}\text { Heart rate } \\
\text { per min) }\end{array}$} & \multicolumn{3}{|c|}{ QRS interval(sec) } \\
\cline { 2 - 4 } & Range & Mean & No. of cases \\
\hline 48 & 0.08 & 0.08 & 1 \\
\hline $51-60$ & 0.1 & 0.1 & 1 \\
\hline $61-70$ & $0.08-0.12$ & 0.1 & 25 \\
\hline $71-80$ & $0.08-0.12$ & 0.1 & 32 \\
\hline $81-90$ & $0.08-0.12$ & 0.1 & 25 \\
\hline $91-100$ & $0.08-0.10$ & 0.09 & 10 \\
\hline $101-110$ & 0.08 & 0.08 & 3 \\
\hline $111-120$ & $0.08-0.10$ & 0.09 & 3 \\
\hline
\end{tabular}

The mean QRS duration decreases with the increase in heart rate. In range of 48 to 90 beats/min QRS interval was steady \& then with increased heart rate showed gradual fall.

There was no subject in whom total voltage of $\mathrm{R}$ $\& \mathrm{~S}$ wave was crossing $35 \mathrm{~mm}$.

\section{ST Segment:}

ST changes were mainly seen in precordial leads. A single subject showed ST depression by $0.5 \mathrm{~mm}$ whereas eight subjects showed ST elevation. Out of eight cases of ST elevation two each were associated with early repolarisation syndrome \& persistent juvenile pattern \& rest were nonspecific.

\section{T wave:}

$\mathrm{T}$ wave showed variable results. The amplitude wasn't exceeding $7 \mathrm{~mm}$ in standard \& unipolar limb leads \& $18 \mathrm{~mm}$ in precordial lead. $\mathrm{T}$ wave in $\mathrm{V}_{5} \& \mathrm{~V}_{6}$ was never found to be less than $1 \mathrm{~mm}$ in height.

$\mathrm{T}$ wave inversion was present in single or more than one lead. Out of 100 subjects, 24 subjects showed $\mathrm{T}$ inversion in $\mathrm{V}_{1}, 11$ subjects in lead III \& 12 subjects in aVL. $\mathrm{T}$ inversion at seven instances was related with Early Repolarisation Syndrome \&rests were nonspecific. There was no correlation between ST elevation or position of heart.

\section{QT interval}

QT interval \& corrected QT interval was calculated with standard formula. ${ }^{3}$ Mean QTc value showed minimal decrease with tachycardia but within a wide range. The following table shows correlation of QTc with heart rate.

\begin{tabular}{|l|c|c|c|}
\hline \multirow{2}{*}{$\begin{array}{l}\text { Heart rate } \\
\text { beats/min) }\end{array}$} & \multicolumn{3}{|c|}{ QTc interval } \\
\cline { 2 - 4 } & Range & Mean & No. of cases \\
\hline 48 & 0.36 & 0.36 & 1 \\
\hline $51-60$ & 0.35 & 0.35 & 1 \\
\hline $61-70$ & $0.34-0.42$ & 0.38 & 25 \\
\hline $71-80$ & $0.33-0.42$ & 0.375 & 32 \\
\hline $81-90$ & $0.34-0.42$ & 0.38 & 25 \\
\hline $91-100$ & $0.34-0.42$ & 0.38 & 10 \\
\hline $101-110$ & $0.32-0.38$ & 0.35 & 3 \\
\hline $111-120$ & $0.32-0.38$ & 0.35 & 3 \\
\hline
\end{tabular}

\section{U Wave:}

Upright $\mathrm{U}$ waves were recorded only in precordial leads in 26 subjects. The predominance was found in $\mathrm{V}_{3}$ (24 subjects) followed by $\mathrm{V}_{1} \& \mathrm{~V}_{6}$.

\section{ABNORMAL RECORD PHYSIOLOGICAL VARIATIONS}

$\boldsymbol{\&}$

Only one subject had right atrial hypertrophy, no other abnormality was detected.

The physiological variations observed are tabulated below

\begin{tabular}{|l|c|}
\hline Physiological variation & No of subjects \\
\hline Early Repolarisation Syndrome & 15 \\
\hline Persistent Juvenile pattern & 4 \\
\hline Sinus Arrhythmia & 12 \\
\hline Nonspecific ST elevation & 8 \\
\hline Nonspecific T changes & 24 \\
\hline
\end{tabular}

\section{DISCUSSION}

The present study not only provides some observations on the range of values found in the electrocardiogram of late adolescents, but also permits certain discussions on the normal variables. It has been noted that the mean heart 
rate in this study is showing a higher value. Packard et al (1954) in an electrocardiographic study of 1000 healthy aviators whose age ranged from 20 to 30 years with the mean age of 23.7 years found that only in $20 \%$ cases heart rates were greater than 100 beats per min \& his mean heart rate was $63.5 / \mathrm{min}$. This could be because of their occupation which requires good physical fitness \& cardiovascular endurance. In the present study, anxiety states during examination \&lack of proper athletic habits which resulted in increased sympathetic activity ${ }^{4}$ can be possible factors for the high value of heart rate.

Desiderio Gross has stated in his study, the duration of $\mathrm{P}$ wave remains unaltered with the increasing heart rate ${ }^{5}$ which is also noted in present study. He has also noted non pointed \& unnotched tall $\mathrm{P}$ wave, when the person breathes against manometric pressure. Rahimtoola has mentioned in his study about the presence of tall $\mathrm{P}$ wave along with sinus tachycardia in tall asthenic individuals with a low diaphragm \& a vertical position of the heart. ${ }^{6}$ The presence of tall $\mathrm{P}$ wave in present study is associated with vertical position of heart.

H.K. Bose(1961) in an electrocardiographic study of 570 young healthy Indian students (age group 16 to 26 years) found that the mean PQ interval was $0.140 \mathrm{sec} \&$ never exceeded more than 0.20 sec. $^{1}$ Packard et al (1954) found PQ interval as $0.154 \mathrm{sec}$ in the age group of 20 to 30 years. Savilathi (1946) thought that only a small percentage of normal subjects may reveal PQ interval above $0.20 \mathrm{sec}$. In this study, the mean PQ interval is $0.14 \mathrm{sec} \&$ in two records the PR interval has crossed $0.20 \mathrm{sec}$ when it was found to be $0.28 \mathrm{sec} \& 0.32 \mathrm{sec}$. The increase of PQ interval normally with age \& bradycardia particularly in young athletic group is well known. ${ }^{1}$ Both the subjects with longer PQ interval in this study were underweight \& showing bradycardia. The short PR interval is a physiological variation due to accelerated $\mathrm{AV}$ conduction as an individual idiosyncrasy.

The $\mathrm{Q}$ wave present in all records was neither slurred nor notched which is similar to that of previous studies of H.K. Bose \& Packard et al. The slurring or notching of the $\mathrm{Q}$ wave can be considered as abnormal. ${ }^{1}$

QRS interval has varied in duration directly with heart rate. The changes with age are significant but not considered in this study due to a very narrow range. Seshadri Balaji had shown the inverse relationship of heart rate with QT interval in adolescents which is similar to the present study. ${ }^{3}$

The $\mathrm{T}$ wave inversion is not necessarily a marker of disease but can also be found as a physiological variation. Inverted $\mathrm{T}$ waves in precordial leads are common in children which usually become upright during pubertal development. They may remain inverted in young asymptomatic adults in $\mathrm{V}_{1}$ to $\mathrm{V}_{3}$ but beyond $\mathrm{V}_{4}$ are usually abnormal. Also the true inversion of $T$ wave in lead $I$ is uncommon in healthy asymptomatics. ${ }^{7,8} \mathrm{~T}$ waves cannot be differentiated in normal or abnormal conditions, but it is said that $\mathrm{T}$ wave is usually shallow \& limbs asymmetrical in normal conditions in contrast to symmetrical version of the $\mathrm{T}$ wave in abnormal conditions. ${ }^{6}$ Hence, clinical correlation is the key to differentiate between benign $\&$ malignant $\mathrm{T}$ inversion. $\mathrm{T}$ wave changes can be seen in physiological conditions like high carbohydrate meal, rotation of heart in clockwise position, impact of the apex against the chest wall, posture, effects of respiration $\&$ the influence of local electrical potential. The reasons in adolescent subjects may be presumed to be the anatomic structure of heart, lungs \& chest wall which are intermediate between that of child \& adult. When negative precordial $\mathrm{T}$ waves are recorded from otherwise normal adolescent, the importance of an exaggerated local proximity effect should be considered. ${ }^{9}$ The pathological causes areanemia, hyperventilation, electrolyte abnormalities, sympathetic stimulation due to any cause, ischaemia, myocarditis, arrythmogenic right ventricular cardiomyopathy, certain drugs, ventricular hypertrophy. ${ }^{6,10}$

In present study, the $\mathrm{T}$ inversion was observed in tall\& thin individuals who have a vertical position of heart. Similar observations in upright position 
with full inspiration in previous study was considered as physiological variation. ${ }^{1}$ This may be mistaken as right ventricular hypertrophy \& strain pattern particularly when ST depression \& $\mathrm{T}$ wave inversion in lead II, III \&aVF are associated. Shah \& Ranganekar found that low $\mathrm{T}$ in lead III, aVL\&aVF is common variation whereas in lead II, $\mathrm{V}_{4}, \mathrm{~V}_{5}$ should be taken as borderline finding. ${ }^{11}$ They concluded that such $\mathrm{T}$ wave changes are the reflex adrenergic activity superimposed on a state of autonomic imbalance with sympatheticotonic preponderance from anxiety. Patel \&Damany (1968) found that $T$ wave inversion in precordialleads claimed as juvenile pattern is asymmetrical \& the depth of inversion decreases from $V_{1}$ to $V_{3}$ leads in age group between 0 to 30 years. ${ }^{12}$

In the present study, tall $\mathrm{T}$ waves were found in 5 cases. In an epidemiological survey of an Indian population, Srikantia\& associates (1964) found tall, peaked $\mathrm{T}$ waves over $10 \mathrm{~mm}$ in 41 out of 941 subjects. ${ }^{13}$ Maj.Gen.R.S.Hoon et al observed the incidence of tall $\mathrm{T}$ waves was $2.5 \%$ whereas Dharamdasa \& Nadarajah (1968) reported very high incidence $(37 \%)$ of precordial $\mathrm{T}$ waves of $10 \mathrm{~mm}$ or more in healthy young male subjects of Ceylon. ${ }^{14,15}$ Tall $\mathrm{T}$ waves were present with vertical or semi vertical position of the heart. Tall $\mathrm{T}$ waves did not differ significantly in duration from normal T waves. ${ }^{14,16}$ Subjects with isolated T wave changes \& no other evidence of any significant disease, showed a significantly increased mortality which is more within first few years after discovery of $\mathrm{T}$ wave change.

In the present study, the $U$ wave was seen in 26 cases only in the precordial leads with the predominance in $\mathrm{V}_{3}$. Similar finding of presence of $\mathrm{U}$ wave in $\mathrm{V}_{2}$ to $\mathrm{V}_{4}$ was observed by Dharamadasa \& Nadarajah. ${ }^{14}$ These findings cannot be generalized as specific significant findings. Since occurrence of the $U$ wave in the precordial leads is not consistent therefore the probable cause for occurrence of $U$ wave in given number of cases cannot be explained. Two parallel hypothesis of occurrence of $U$ wave are said to be repolarisation of Purkinje system ${ }^{17}$ or mechanoelectrical hypothesis ${ }^{18}$. Since the individuals in whose electrocardiogram $U$ wave was found were generally tall \& thin, these findings in the present study can be considered as normal variation. There is need of further research for hypothesis of $\mathrm{U}$ wave genesis as well as relation between built \& genesis of $U$ wave. In the present study all $U$ waves observed were upright. $\mathrm{U}$ wave should be always analysed in relation with $\mathrm{T}$ wave for abnormality. Negative waves are always abnormal \& associated with many disorders like valvular heart disease, myocardial infarction, hypokalemia etc. ${ }^{19}$

It is observed that there is a general tendency to vertical position of heart in the young age group as most of the individuals were tall \& lean.

The physiological variation as early repolarisation syndrome is well recognized in electrocardiographic findings. It is seen in approximately 1$2.5 \%$ of healthy teenagers, young adults, male athletes $\&$ is more common in young blacks. ${ }^{20,21}$ Some studies conclude that there is no racial variation. Criterion for its diagnosis is the presence, in at least two adjoining leads, of $\geq 1$ $\mathrm{mm}$ or $0.1 \mathrm{mV}$ ST segment elevation. ${ }^{21,22,23}$ The physiological basis for this physiological variation is not well established, but it is considered a result of early onset of repolarisation of the ventricle in a nonhomogeneous mannerpreceded by the epicardial surface vector.

Earlyrepolarisation syndrome \& persistent juvenile pattern sometimes closely mimic pericarditis or patterns of epicardial injury. Recent studies show positive association of early repolarization (ER) with the risk of lifethreatening arrhythmias in patients with coronary artery disease (CAD).Early repolarisation mainly in inferior leads with a horizontal/descending ST variant was associated with increased risk of cardiac events 24 whereas some studies have not obtained association between any component of early repolarisation with cardiac mortality. 25 Normal juvenile symmetrical $\mathrm{T}$ wave inversion cannot be differentiated from $\mathrm{T}$ wave inversion due to organic disease. 6 
The only abnormal finding in present study was right atrial hypertrophy. Though this is uncommon finding in asymptomatic individuals but has been noted in previous study. ${ }^{26}$ It has been noted that there is increase in sudden cardiac death in young population. $^{27,28}$ The correlation between the sudden cardiac death \& abnormal findings need to be established.

\section{CONCLUSION}

The electrocardiography, presently, is a widely used method for detection of various cardiovascular diseases. It is a rapid, safe \& reliable method. The interpretation of most electrocardiographic contour abnormalities involve clinical correlation \& thus their diagnostic reliability depends on specificity, sensitivity \& predictive accuracy of given pattern. ${ }^{2}$ Only after deciding what is normal \& its variants, it is possible to discriminate the abnormalities in right way. The present study was undertaken to assess the normal variations in the electrocardiogram of asymptomatic individuals in the age group of 15 to 19 yrs. Aim of the study was to observe the normal \& abnormal electrocardiographic changes $\&$ its physiological variations in late adolescents. In this study, 100 asymptomatic individuals' electrocardiograms have been analyzed. Average, minimum \& maximum values of different waves have been put up in the tabulated form. Stress has been laid on physiological variations \& evaluation of borderline findings. The present study is an attempt to assess the normal variations in a small sample size. As these physiological variations may mislead to serious cardiovascular diseases, there is a need to conduct more studies over a wide range of population, so as to minimize possible errors for detection \& establishment of physiological variation as risk factor for cardiovascular diseases.

\section{ACKNOWLEDGEMENT}

I sincerely thank Dr. Prakash Sonarikar, MD (Medicine) for his guidance.

I also thank Mr. Abhijeet Thakur for technical assistance.

\section{REFERENCES}

1. H.K. Bose.Electrocardiographic study of 570 young healthy Indian students (between the age group of 16 to 26 years) with statistical analysis \& data. Indian Heart Journal 1961.April;114-140

2. Arthur Selzer. The Bayes theorem \& clinical electrography. Am. Heart J;1981 Mar;101(3):360-363

3. Seshadri Balaji, Yung $\mathrm{R}$ Lau, Paul C Gillette, Effect of heart rate on QT interval in children \& adolescents. Heart. 1997,77; 128-129

4. Viitasalo MT,Kala R, Eisalo A. Ambulatory electrocardiographic findings in young atheletes. Eur Heart J. 1984 Jan; 5(1):2-6

5. Desiderio Gross , M.D. \& Santiago, Chile, Contributions to the functional morphology of the $\mathrm{P}$ wave, Am. Heart J.1961, April;436 -444

6. Charles Fisch, MD, Abnormal ECG in clinically Normal Individuals. JAMA. 1983,Sept;250(10) :1321-1323

7. Ronald G.Hiss, Capt. USAF (MC), \& Lawrence E. Lamb ,M.D. Electrocardiographic Findings in 122,043 individuals, Circulation. 1962,June; XXV:947-961

8. Hiss RG, Lamb LE, Allen MF, Electrocardiographic findings in 67375 asymptomatic subjects $\mathrm{x}$. normal values, Am J Cardiol.1960, 6:200-231

9. Norman S.Blackman, M.D. \& Lawrence Kuskin , M.D. Inverted $\mathrm{T}$ Waves in the precordial electrocardiogram of normal adolescents . Am. Heart. J. 1964,March; 67(3):304-312

10. Aapo L. Aro, Olli Anttonen, Jani T. Tikkanen, TuomasKerola, HarriRissanen. Prevalence \& prognostic significance of Twave inversions in Right Precordial Leads of a 12- Lead ECG in the middle Aged subjects Arrythmia/ Electrophysiology

11. V.V. Shah \& S. B. Ranganekar. Twelve Lead Normal Adult Electrocardiogram, Indian Heart Journal. 1953,January:25- 43 
12. Dinesh Patel \&S.J. Damany Juvenile $\mathrm{T}$ Waves (A study of 100 Cases) Indian Heart Journal.1968,January:39-41

13. SRIKANTIA, S.G., PADMAVATI, S., \& GOPALAN C .The electrocardiogram in some Indian population group. Circulation. 1964, 29:188

14. Maj. Gen. R.S. Hoon, Maj. M. Durariraj, Maj. M.G. Sahadevan, \& Capt. V. Balsubramanian. Tall $\mathrm{T}$ waves in precordial leads incidence in adult Indians with otherwise normal electrocardiogram. Indian Heart Journal.24(4):333-336

15. K. Dharmadasa \& M. Nadarajah Electrocardiograms in young Ceylonese, Br Heart Journal, 1968:30,765 Charles Fisch, MD, Abnormal ECG in clinically Normal Individuals.JAMA.1983, September; 250(10):1321 -1323

16. Charles E. KIESSLING, M.D., ROYAL S. SCHAFF, M.D. \& ANNIE MARY LYLE, F.S.A.A study of $\mathrm{T}$ wave changes in the Electrocardiogram of normal individuals. The American Journal of Cardiology. 1964,May: 598-602

17. Hlaing T, DiMino T, Kowey PR, Yan GX ECG repolarization waves: their genesis \& clinical implications. Ann Noninvasive Electrocardiol . 2005 Apr; 10(2): 211-23

18. Surawicz B U Wave: facts, hypotheses, misconceptions, \& misnomers. J Cardiovasc Electrophysiol. 1998 Oct; 9(10): 1117-28

19. Brian A. Dalrymple, Laszlo Littmann. Large negative $\mathrm{U}$ waves associatedd with hypokalemia. Case reports in Internal Medicine 2015;2(1):69-72

20. Araoye MA The physiological basis of ST-T variations in the electrocardiogram: a review. Afr J Med Med Sci. 1994 sep; 23(3):201-205

21. Perez- Riera AR, Abreu LC, Yanowitz F, Barros RB, Femenia F, Mclntyre WF, Baranchuk A. "Benign" early repolarization versus malignant early abnormallities: clinical - electrocardio- graphic distinction \& genetic basis. Cardiol J. 2012;19(4):337-46

22. Hirofumi Kambara, MD John Phillips, MD, FACC. Long term evaluation of Early repolarisation syndrome (physiological variation RS-T segment elevation) The American Journal of Cardiology. 1976, August;38:157-161

23. Uberoi A, Stein R, Perez MV, et al. Interpretation of the Electrocardiogram of Young Athletes. Circulation 2011; 124(6): 746-757. doi:10.1161/CIRCULATIONAHA.110.013078

24. Lee HY, Mun HS, Wi J, Shim J, Kim JY, Pak HN, Lee MH, Joung B Early repolarization \& myocardial scar predict poorest prognosis in patients with coronary artery disease. Yonsei Med J. 2014 Jul; 55(4): 928-36 doi:10.3349/ymj.2014.55.4.928

25. Uberoi A, Jain NA, Perez M, Weinkopff A, Ashley E, Hadley D, Turakhia MP, Froelicher V. Early repolarization in an ambulatory clinicalpopulation . Circulation 2011,Nov 15;124 (20): 2208-14 doi: 10. 1161/CIRCULATIONNAHA.111.047191. Epub2011 oct 10.

26. Blair Riddle; Dr. Poulina Uddin; Dr. Sara Yu Choung; Ngoc-Ha Ngo; Dr. John Rogers, Normal ECG Measurements in the Adolescent Population. Available on Blair_Riddle_2013-14_HonorsProject.pdf

27. BMC Cardiovascular Disorders__Fulltext_ Early repolarization with horizontal ST segment may be associated with aborted sudden cardiac arrest_a retrospective case control study

28. American College of Cardiology Foundation_ Journal of American College of Cardiology_ Sudden Cardiac Death in Young Atheletes Practical Challenges and Diagnostic Dilemmas. 